\title{
Assessment of Wind Power Potential at Eastern-Jerusalem, Palestine
}

\author{
Husain R. Alsamamra1 ${ }^{*}$, Jawad Ali Hasan Shoqeir ${ }^{2}$ \\ ${ }^{1}$ Department of Physics, Al-Quds University, Jerusalem, Palestine \\ ${ }^{2}$ Department of Earth and Environmental Sciences, Al-Quds University, Jerusalem, Palestine \\ Email: ^hsamamra@staff.alquds.edu
}

How to cite this paper: Alsamamra, H.R. and Shoqeir, J.A.H (2020) Assessment of Wind Power Potential at Eastern-Jerusalem, Palestine Open Journal of Energy Efficiency, 9, 131-149.

https://doi.org/10.4236/ojee.2020.94009

Received: November 17, 2020

Accepted: December 27, 2020

Published: December 30, 2020

Copyright $\odot 2020$ by author(s) and Scientific Research Publishing Inc. This work is licensed under the Creative Commons Attribution International License (CC BY 4.0).

http://creativecommons.org/licenses/by/4.0/

(c) (i) Open Access

\begin{abstract}
Due to the energy demand and lack of supplied energy of Palestinian cities, wind resource assessment is important and necessary. The objective of the work is to analyze the wind speed data characteristics and wind power potential at eastern Jerusalem that are collected at $10 \mathrm{~m}$ above ground level from 2008 to 2018. The variations of monthly, seasonal, and annual wind speed are analyzed, and the measured maximum, minimum, and mean values are presented in this study. Wind speed characteristics have been analyzed by the well-known Weibull distribution function, and used to evaluate the wind power of the proposed site. Moreover, the relationship between wind power and mean wind speed is fitted by a second-order polynomial. The shape parameter moderate values showed that wind speed was relatively steady at the site. The highest average maximum value was found to be $5.7 \mathrm{~m} / \mathrm{s}$ in June-2008, whereas the mean maximum values ranged from $5.4 \mathrm{~m} / \mathrm{s}$ in June to $3.8 \mathrm{~m} / \mathrm{s}$ in November. The highest mean power value was found to be 31.66 $\mathrm{w} / \mathrm{m}^{2}$ in July with a maximum value of $23.18 \mathrm{w} / \mathrm{m}^{2}$ in $2013 . \mathrm{R}^{2}$ of the polynomial fit provides values of $95 \%$ for monthly mean and $96 \%$ for annual mean.
\end{abstract}

\section{Keywords}

Wind Speed, Weibull Parameters, Wind Power, Polynomial Fit, Palestine

\section{Introduction}

Palestine faces a critical situation with regard to achieving sustainable development. Many problems contributed to the continuous deterioration of the political, economic, social and environmental conditions, and hindered development initiatives. For nearly four decades, the lack of Palestinian infrastructure has 
impeded any realistic energy progress [1]. The conventional energy shortage of resources and limited renewable resources have led to unrealistic price control, shortage of energy and a future energy crisis [2]. In addition, the Palestinian energy sector is insecure and therefore different compared to other neighboring countries in the Middle East, for several reasons: lack of natural resources, unstable political conditions, financial crisis, and high population density. Moreover, Palestine relies on other countries for $100 \%$ of its fossil fuel imports and $87 \%$ of its electricity imports [3]. In addition, high population growth, high living standards and rapid growth of industry have resulted in an enormous demand for energy in Palestine in recent years.

Despite all these challenges, Palestine went ahead with using its natural resources for rehabilitation and construction. Renewable wind energy provides a practical and inexpensive solution to distribute generators of power to vast regions around the world. It has become one of the most convenient and environmentally friendly ways to generate electricity [4]. According to the global wind energy council, the total world capacity from wind power system was over $651 \mathrm{GW}$ in 2019, which means that $60.4 \mathrm{GW}$ of wind energy capacity was installed globally in 2019 [2]. Most of the commercial wind turbines operate today at sites with an average wind speed of around $5 \mathrm{~m} / \mathrm{s}$ [5]. The wind speed variation on a wind turbine is very complex and demands sophisticated techniques to optimize power extraction. The most important parameter of wind energy is the wind speed and the analysis of wind data variations. In recent years, a number of studies have been carried out to find the specific distribution of wind speeds in order to use in practical applications as the estimation of wind loads on building and power analysis. Mathematical models were used to study wind speed data and in this study, the two-parameter Weibull distribution is used to characterize wind speeds. The daily average wind speed can be described with reasonable accuracy by Weibull distribution parameters, the dimensionless shape parameter $\mathrm{k}$ and the scale parameter $\mathrm{c}$ in units of $\mathrm{m} / \mathrm{s}$ [6] [7] [8]. The prediction of wind energy output which is required for the assessment of wind power plants can be constructed by the results of the Weibull distribution with acceptable accuracy [9].

Numerous studies in the literature and extensive research interests in recent years have considered the description of wind speed variations by the use of probability density function models. Luna and Church (1974), studied the use of lognormal distribution as a universal distribution of wind speed, however, due to the differences in climate and topography, it was realized that a universal distribution may not be applicable [10]. This fact was supported by a recent work done by Zhou et al. (2010), which the effectiveness of conventional and non-conventional statistical distributions was investigated and compared for characterizing the wind speed characteristics at multiple North Dakota sites [11]. There is no adequate universal distribution function that outperforms the others for all sites. In general, Weibull statistical distribution with its shape and scale 
parameters was found to be the most widely adopted for representing the wind speed [12] [13] [14] [15]. Meanwhile, other proposed probability distribution functions have been used to study wind speed variations, including Rayleigh distribution, which is a special case of Weibull distribution; lognormal distribution, in which the logarithm values variation follows normal distribution; gamma distribution, which represents the sum of exponentially distributed random variables; as well as inverse Gaussian and generalized extreme value distributions [16].

Justus et al. (1978) applied the Weibull distribution to study the surface wind speed United States and calculated the power output from wind generation. They found that Weibull was an adequate model and describes well the variations of the wind speed [12]. Van der and Auwera et al. (1980) examined four statistical distributions to fit the observed wind speeds in Belgium. Results showed that the Weibull distribution function gives the best fit. Weibull distribution can be easily used to determine wind power once the mean of the cube of the wind has been calculated [17]. The two parameters of Weibull distribution function for daily mean wind speeds were calculated by Rehman et al. 1994 [18] for 10 locations in the kingdom of Saudi Arabia. The shape parameter values ranged from 1.7 to 2.7 , whereas the scale parameter varied from $3 \mathrm{~m} / \mathrm{s}$ to $6 \mathrm{~m} / \mathrm{s}$. The authors concluded that the Weibull distribution function presented a good fit for the wind speed data.

Celik in 2003 [19] estimated the energy output for small-scale wind power generators using Weibull distribution to represent wind data for 5 different areas around the world. He used the Weibull-representative wind speed for a total of 96 months to estimate the monthly wind energy production in these areas. Rehman and Al-Abbadi 2008 [20] studied the variation of the shape and scale parameters through analyzing the characteristics of wind speeds collected at different altitudes above ground level in the kingdom of Saudi Arabia. They concluded that, the Weibull shape parameter value is independent of altitude unlike the scale parameter.

Kitaneh et al. 2012 [3] studied the wind energy in four areas at Palestine in the period (1997-2001), they applied the Weibull function and the parameters were derived from the cumulative function. They observed that most locations presented the highest monthly mean wind power density during summer and the lowest value during winter.

A study by Bassyouni et al. 2015 [21] in Jeddah found that the wind speed for Jeddah is higher for months of March to August. In the analysis, 10 years of wind data were used to find the Weibull parameters and also the average wind speeds. It was also recommended to install smaller turbines than larger ones since the wind average calculated ranged between $2.866 \mathrm{~m} / \mathrm{s}$ and $3.875 \mathrm{~m} / \mathrm{s}$.

According to Mohammadi et al. 2016 [22], it was found that different sites used different methods of Weibull parameter estimation since the wind characteristics of the site determine that best approximation method. Kombe et al. [16] 
used the Weibull distribution function to fit 10 years of monthly mean wind speed data of Great Cumbrae Island. The calculated mean wind speed was 7.598 $\mathrm{m} / \mathrm{s}$ and the wind power density calculated for the region was $483.50 \mathrm{~W} / \mathrm{m}^{2}$.

To sum up, one of the possible solutions to cover the lack of energy in Palestine is generating electricity from wind, however it is necessary for wind power potentials to study wind speed variations at a site. In the present work, the daily values of wind speed of 11 years data were analyzed and used to develop the Weibull distribution model and used to estimate the wind power at a site located in eastern Jerusalem in Palestine. The data were analyzed at the daily, monthly, seasonally and yearly basis, the Weibull parameters were obtained, and the potential of wind power was evaluated for the site.

\section{Study Area and Dataset}

The energy service in Palestine has become so expensive that it can no longer be afforded by a large portion of the people who are suffering from poverty and scarcity of possibilities. The largest supplier of electricity to the Palestinian electricity sector is Israel Electric Corporation with about $87 \%$ of the total consumption, this dependency imposed a different reality in terms of need and efficiency [3] [21]. The Israeli restrictions on the ground have made the Palestinian energy market with limited options for developing indigenous sources of electricity. The Israeli control over Area C, which constitutes $60 \%$ of the West Bank and is characterized by open lands, has prevented the construction of electricity networks in addition to the establishment of renewable energy projects in these areas [2] [22] [23]. Due to the lack of natural energy resources and in order to reduce dependency on energy sources, Palestinians are strongly required to search for renewable and sustainable energy sources such as wind energy. However, wind speed must be studied based on the available data in order to generate electricity from wind.

Wind speeds in Palestine are moderate [5]. The characteristic of wind speed is very low throughout the year in the coastal regions, with an annual average of $2.5-3.5 \mathrm{~m} / \mathrm{s}$, the annual average wind speeds in Jordan Valley around $2-3 \mathrm{~m} / \mathrm{s}$. While the hilly regions of the West Bank have average wind speeds varying in the range of 4 to $8 \mathrm{~m} / \mathrm{s}$ annually [6]. Mountains regions have wind speed reaches $5 \mathrm{~m} / \mathrm{s}$ [3].

The city of Jerusalem is located at $31.77^{\circ} \mathrm{N} 35.22^{\circ} \mathrm{E}$ with a height of $780 \mathrm{~m}$ above sea level as presented in Map 1. The average annual maximum and minimum air temperature of the study region ranging from $21.0^{\circ}$ to $11.0^{\circ}$ Celsius in the year 2018, with higher air temperature in July month and lower air temperature in January.

The daily data of air temperature, atmospheric pressure, and wind speed for 11 years era from January-1-2008 to December-31-2018 recorded by a weather station located at a height of $100 \mathrm{~m}$ above the ground level in east Jerusalem were provided by the Palestinian meteorological station's network office. Wind 


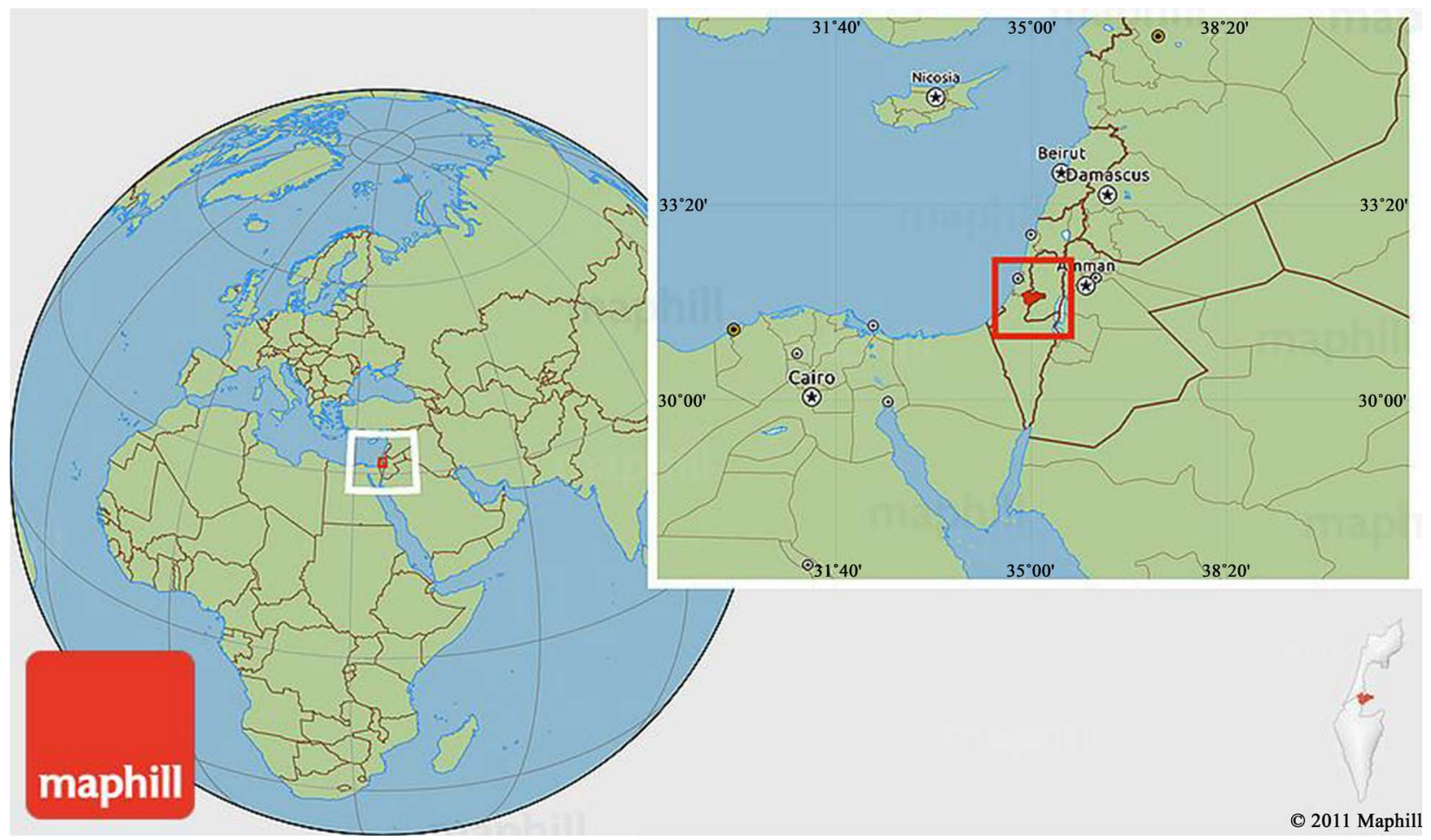

Map 1. Location of Jerusalem city.

speed data were recorded 8 times a day by a cup generator anemometer. Unfortunately, about $2 \%$ of the observed data were missing, this is due to calibration, servicing, and malfunctioning machines.

\section{The Weibull Probability Distribution Function}

Wind speed is the main component of wind energy, as the evaluation of wind speed energy in a region depends mainly on the accurate determination of the probability distribution of wind speed values in that region. Previous studies reviewed several distribution functions in order to analyze wind speed, but the two-parameter Weibull distribution was found to be the most simple, accurate and effective [3] [24] [25] [26]. One of the advantages of the Weibull distribution function when applied to natural phenomena is that it provides a close approximation of the laws of probability. This leads to providing a good fit to the experimental data in addition to flexibility and simplicity of application. Besides the advantages of the Weibull distribution mentioned in previous studies, Weibull function has its limitations: it is poor and cannot precisely represent the probabilities of 0 and very low wind speed values with high accuracy [27].

Several recent studies have been conducted in order to build adequate statistical model that provides an appropriate description of the wind speed distribution. Several models were compared in order to obtain a model that is representative to the experimental wind data [20] [21] [22] [28] [29]. Nevertheless, it was found that Weibull distribution model is the most representative and provides a good fit to wind speed experimental values [30]. 
The general mathematical form of the shape and scale parameters Weibull distribution function can be written as [3] [18] [31]:

$$
f(v)=\left(\frac{k}{c}\right)\left(\frac{v}{c}\right)^{k-1} \exp \left[-\left(\frac{v}{c}\right)^{k}\right]
$$

Equation (1) expresses the probability $F(v)$ as a function of observing wind speed $v$, the dimensionless Weibull shape parameter $k$, and the so-called Weibull scale parameter $\mathrm{c}$ in units of $\mathrm{m} / \mathrm{s}$.

As a consequence, $F(v)$ is the cumulative distribution function and can be expressed as [3] [19] [32]:

$$
F(v)=1-\exp \left[-\left(\frac{v}{c}\right)^{k}\right]
$$

The reasonable fitting of the cumulative distribution function lead to the determination of the Weibull $k$ and $c$ parameters. This can be done by taking the natural logarithm twice of both sides of Equation (2) as expressed in Equation (3)

$$
\ln (-\ln [1-F(v)])=k \ln (v)-k \ln c
$$

A straight line graph can be obtained plotting $\ln (-\ln [1-F(v)])$ versus $\ln (v)$, the slope of this straight line represents $k$ while the $\mathrm{Y}$-intercept is $-k n c$. In this work, the Weibull function was fitted to the measured wind speed data by the linear least-square algorithm [3] [27] [33] [34].

The obtained two-Weibull parameters $k$ and $c$ from Equation (3) are representing a close relation to the mean wind speed value $V_{W}$ as proposed and documented by ref. [3] [6] and given by:

$$
v_{w}=c \Gamma\left(1+\frac{1}{k}\right)
$$

where $\Gamma$ is the gamma function.

The resulted Weibull probability density function based on experimental wind speed data used to calculate the mean power density which is a function of the cube of wind speed as expressed in equation (5):

$$
P=\frac{1}{2} \rho v^{3}
$$

Equation (6) represents the air density $\rho$ which is a function of air pressure $B$ and temperature $T, \rho_{0}=1.226 \mathrm{~kg} / \mathrm{m}^{3}$ (density of dry air at standard atmospheric conditions with temperature equal 288 Kelvin and pressure of $760 \mathrm{~mm} \mathrm{Hg}$ ) [3]:

$$
\rho=\rho_{0}\left(\frac{288 B}{760 T}\right)
$$

In consequence, according to Equation (5), the use of the actual mean wind speed or that obtained from a Weibull fit underestimates the true mean power density, and this will not lead to the correct picture with respect the power density. Due to the highly variance in wind speeds; thus the cube of the average 
wind speeds is much less as compared the average of the cube wind speed values [3] [18]. Hence there is a need to adjust the mean power density given in Equation (5) by introducing the correction Energy Pattern Factor (EPF) which is given by:

$$
\mathrm{EPF}=\frac{\text { Mean power density for the month }}{\text { Mean power density at the monthly mean }}
$$

In similar manner, EPF for the season and annual wind speed data can be calculated. Equation (7) provides more accurate and realistic mean power density.

$$
P=\frac{1}{2} \rho(E P F) v^{3}
$$

The Weibull monthly, seasonally and yearly mean wind speed in this work is used to obtain the mean power density from Equation (7) for the represented period.

\section{Results and Discussion}

In this study, 11 years wind speed data at $10 \mathrm{~m}$ height above the ground from January 2008 to December 2018 at eastern Jerusalem, were analyzed at daily, monthly, seasonally and yearly basis. The Weibull function parameters were used to estimate the wind power. Finally, a comparison of the observed versus estimated values of wind speed was conducted.

The following sections are a discussion of the obtained results.

\subsection{Wind Speed Analysis}

The daily maximum, mean and minimum wind speeds are presented in Figure 1. It can be seen that the wind speed fluctuations are very high at the beginning and at the end of the years (Day 0 represents 1 January of the respective year), however, at the mid of the years the pattern seems to be relatively the same. During the period from 2008 to 2018, the maximum wind speed values range between 2 to $14.5 \mathrm{~m} / \mathrm{s}$, the minimum values ranged from 0 to $8.5 \mathrm{~m} / \mathrm{s}$ and the mean values ranged from 1.5 to $10 \mathrm{~m} / \mathrm{s}$. The maximum wind speed value was found in 12 December 2010. Over the period of study, it was found that all years recorded maximum daily wind speeds of greater than $10 \mathrm{~m} / \mathrm{s}$ at the first part of each year except 2014 and 2017, while, at the end part of the years, the same result obtained in the years 2008-2010, 2012-2013. At the mid part of the years, the maximum, minimum and mean values follow the same pattern and are comparatively relatively steady.

The wind speeds of the daily maximum, minimum and mean values were averaged over the period of study and plotted as shown in Figure 2. The calculated average values showed higher values at the mid part, with the average maximum, minimum and mean values ranged respectively from 3.2 to $5.7 \mathrm{~m} / \mathrm{s}, 0.8$ to 2.2 $\mathrm{m} / \mathrm{s}$ and 2.1 to $4 \mathrm{~m} / \mathrm{s}$. 
The monthly averaged wind speeds are shown for the period along with their mean in Figure 3. The highest maximum wind speed value was found to be 5.7 $\mathrm{m} / \mathrm{s}$ in June 2008 , while the lowest maximum value was $3.1 \mathrm{~m} / \mathrm{s}$ in November 2010, however, the obtained monthly averaged maximum values over the period presents highest value $(5.4 \mathrm{~m} / \mathrm{s})$ in June and lowest value $(3.8 \mathrm{~m} / \mathrm{s})$ in November.
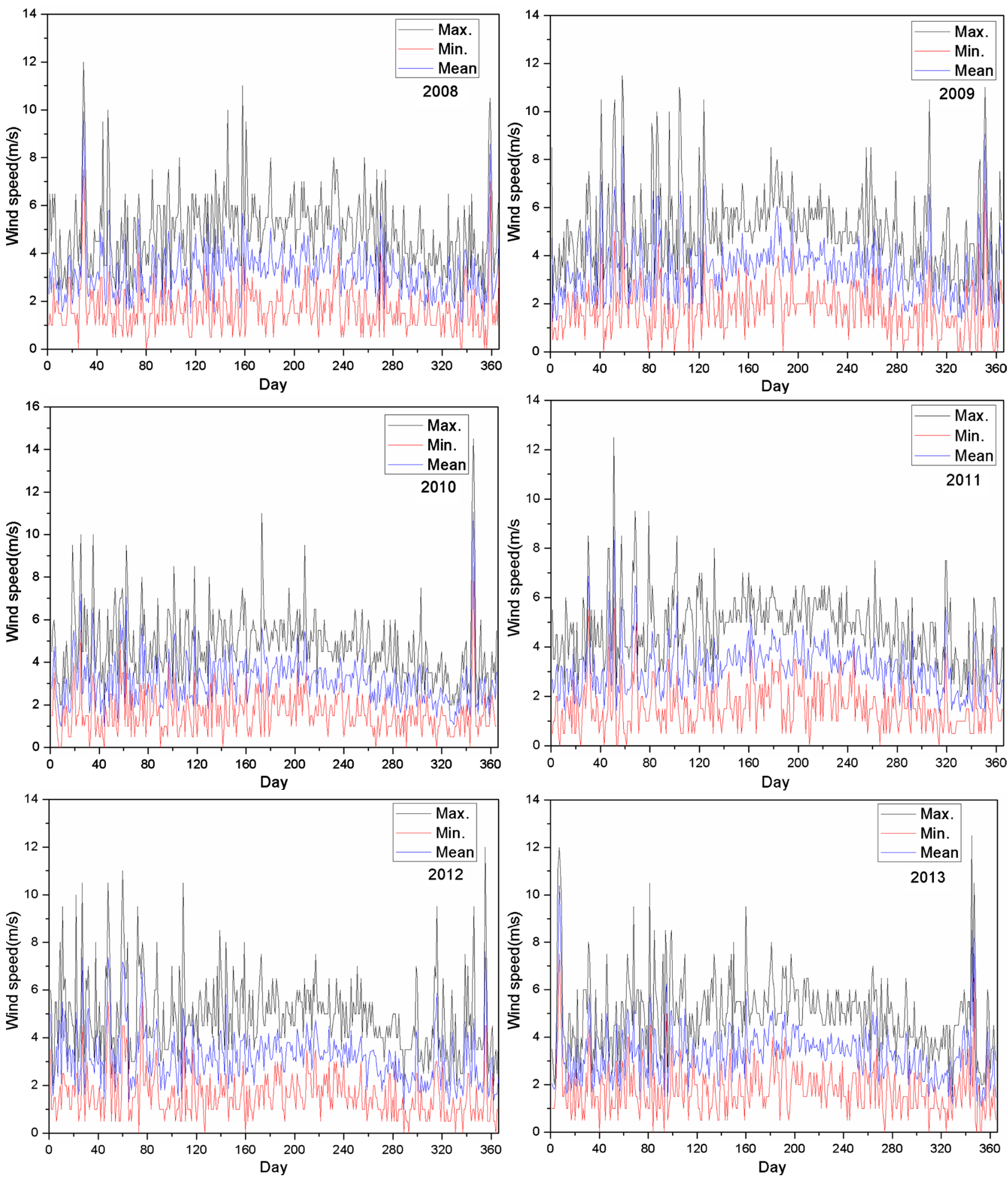

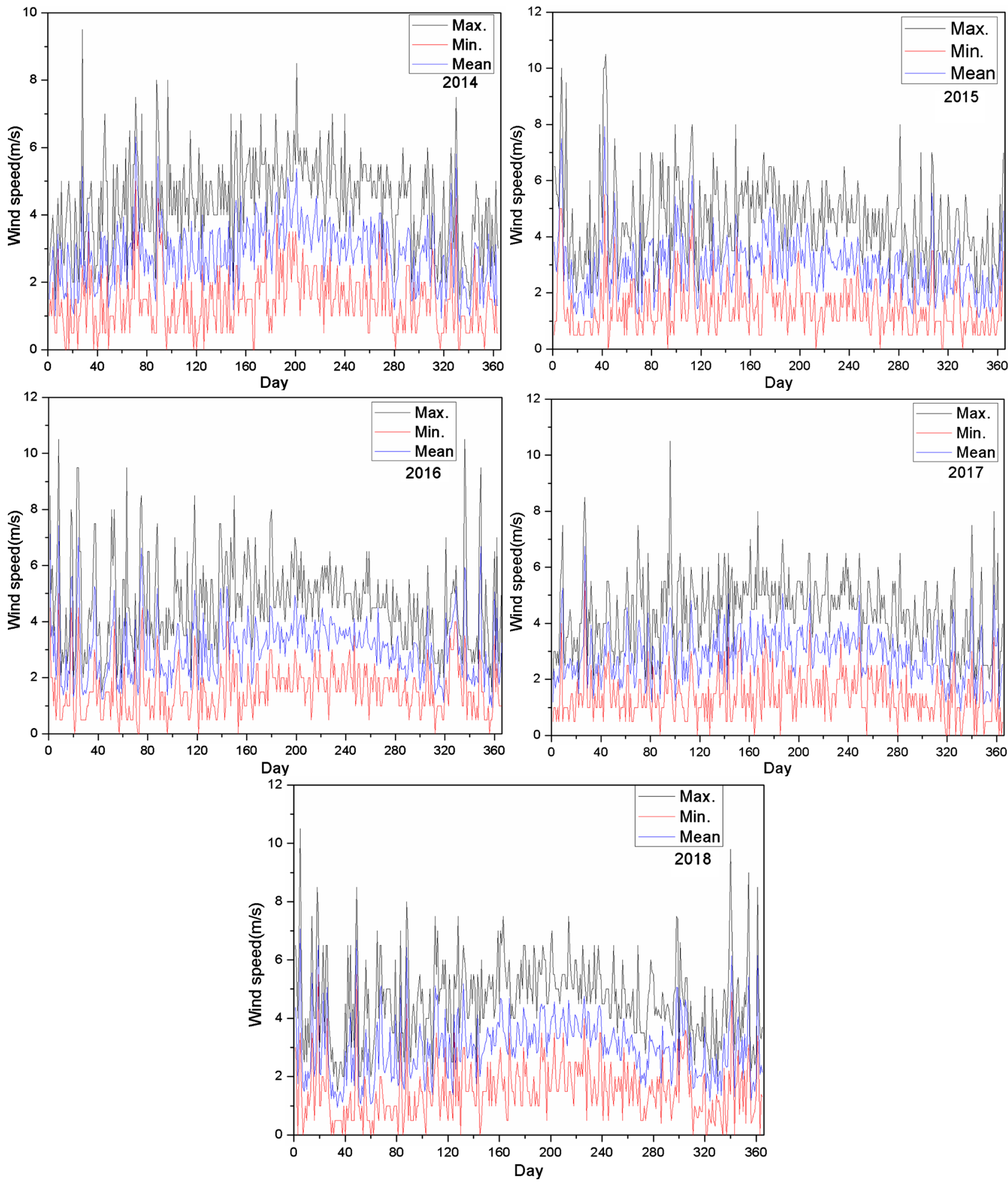

Figure 1. Daily mean, maximum and minimum wind speed values of each year for the period from 2008 to 2018.

The highest and lowest minimum wind speed values respectively varied from 2.3 to $1 \mathrm{~m} / \mathrm{s}$ observed in July 2009 and November 2011, whereas the monthly averaged minimum values along the period ranged from $2 \mathrm{~m} / \mathrm{s}$ in July to $1.2 \mathrm{~m} / \mathrm{s}$ in November. Overall, the monthly mean values varied from $3.7 \mathrm{~m} / \mathrm{s}$ in July to 


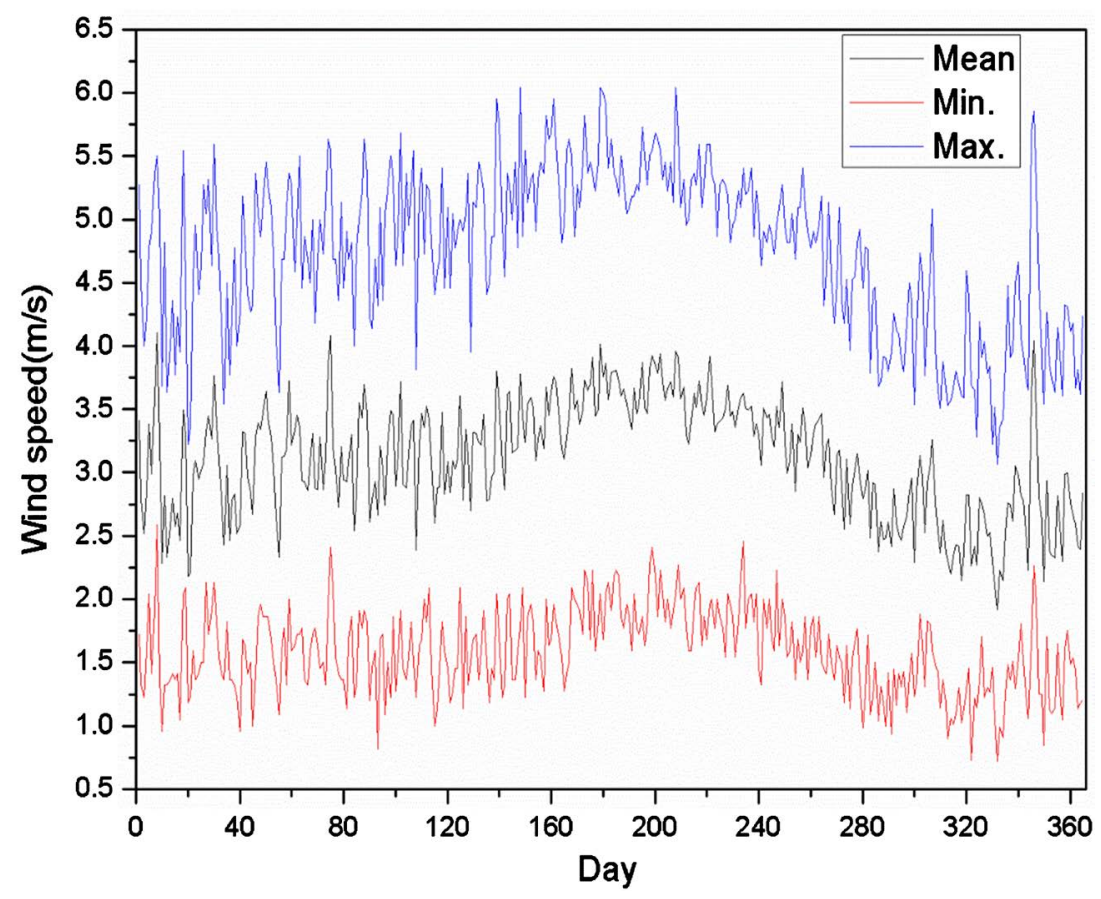

Figure 2. Daily averages of mean, maximum and minimum wind speed values for the period from 2008 to 2018 .

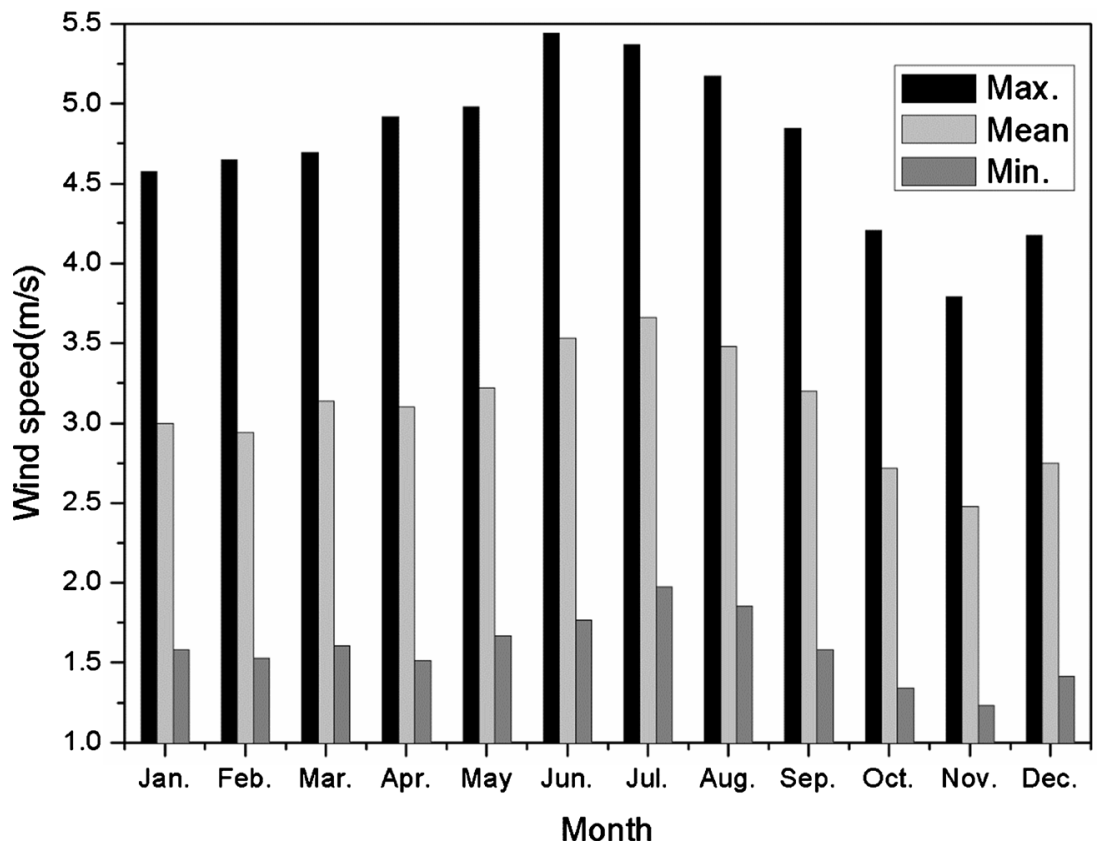

Figure 3. Monthly averages of mean, maximum and minimum wind speed values for the period from 2008 to 2018 .

$2.5 \mathrm{~m} / \mathrm{s}$ in November, while highest mean $(4.2 \mathrm{~m} / \mathrm{s})$ was found in July 2009 and the lowest mean $(2.1 \mathrm{~m} / \mathrm{s})$ in November 2010 .

Figure 4 presents a comparison of the seasonal averages of mean wind speed values for each year. The wind speed data was classified into four seasons for each year: spring (March to May), summer (June to August), autumn (September 


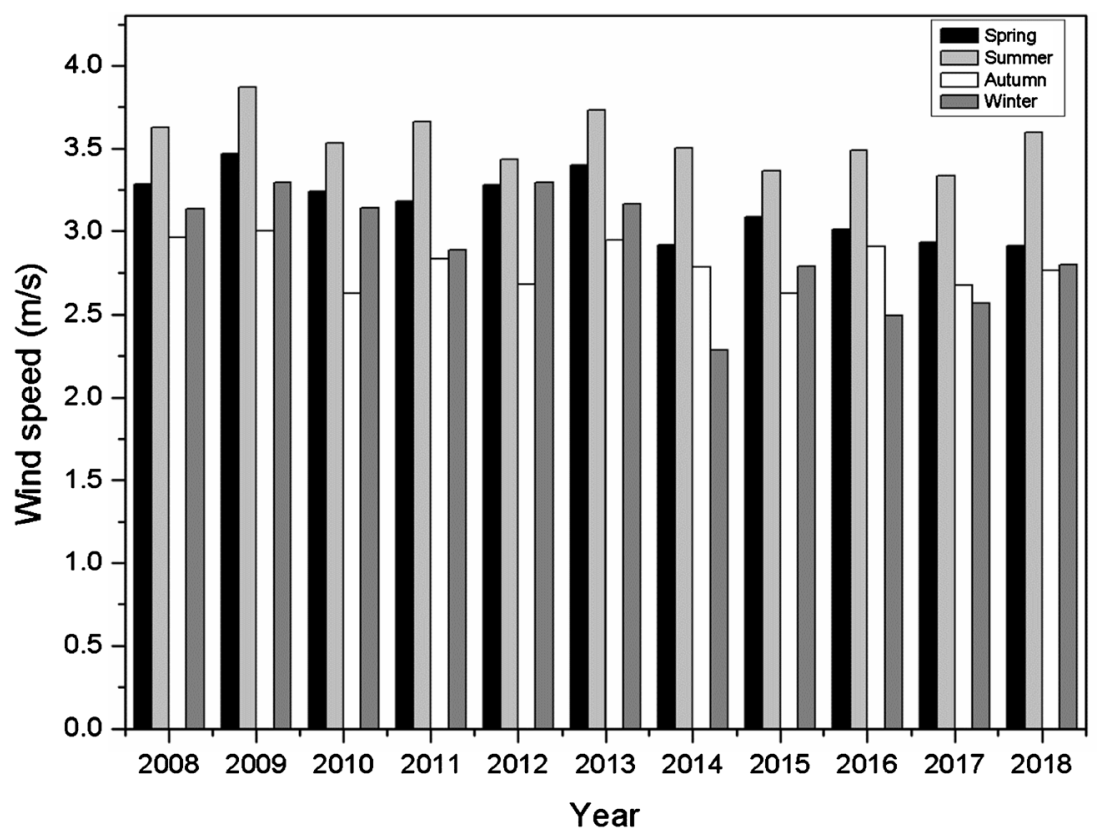

Figure 4. Seasonal averages of mean wind speed values for each year of the period from 2008 to 2018 .

to November), and winter (December to February). From the results, it was observed that summer seasons are mostly windier. As evident from the monthly average analysis, summer seasons along the period from 2008 to 2018 provides higher average mean wind speeds with a maximum value of $3.9 \mathrm{~m} / \mathrm{s}$ in 2009 , followed by spring seasons. The lowest value was observed to be $2.3 \mathrm{~m} / \mathrm{s}$ in winter 2014. Overall, winter seasons average mean wind speed values found to be greater than autumn seasons except in 2014 and 2016-2017.

The annual averages of mean wind speed values from 2008 to 20018 were further analyzed and presented in Figure 5. As a consequence evidence of the previous analysis, the observed highest and lowest annual mean wind speed values being $5.16 \mathrm{~m} / \mathrm{s}$ to $4.2 \mathrm{~m} / \mathrm{s}$ for the years 2009 and 2017 respectively. The annual variations are highly influence and attributed to the seasons and thus the occurrence of annual variations is very important in the exploitation of wind resources because it has a great influence on the production of wind turbines in the long-term.

\subsection{Weibull Parameters and Wind Power Analysis}

The monthly average mean wind speed, Weibull parameters, i.e., $\mathrm{k}, \mathrm{c}$ and $\mathrm{v}_{\mathrm{w}}$ calculated by Equations (3) and (4), specific wind characteristics $\left(v_{\text {avg }}^{3}, v_{\text {avg }}^{3}\right.$ and $\mathrm{EPF}$ ), and wind power calculated using Equation (7) of the site for the period (2008-2018) are summarized in Table 1, seasonal and annual measurements are presented respectively in Table 2 and Table 3 . The average value of the k parameter for the monthly basis is 2.24 with a maximum value of 2.78 in July and minimum value of 1.77 in November. Maximum shape parameter with value of 2.01 was in 2014, while the minimum was in 2015 with a value of 1.75 . Seasonally, 


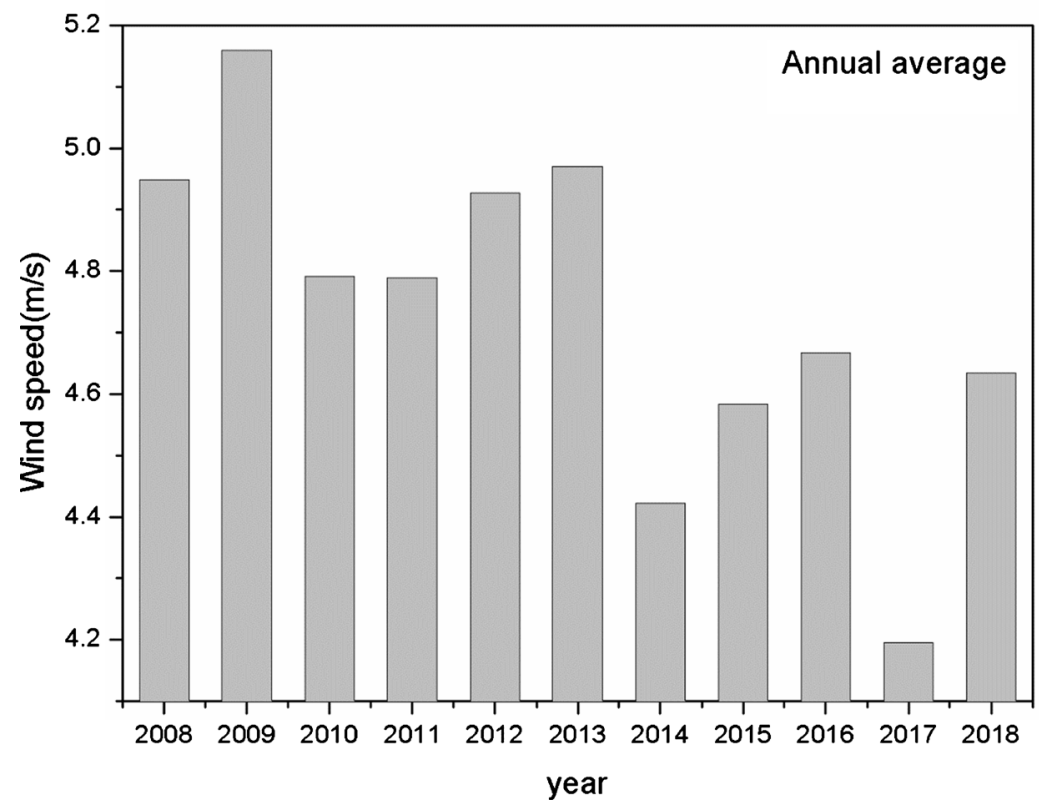

Figure 5. Annual averages of mean wind speed values for each year of the period from 2008 to 2018.

Table 1. Monthly mean wind speed characteristic parameters for the period 2008-2018.

\begin{tabular}{ccccccccc}
\hline Months & $\begin{array}{c}V_{\text {obs }} \\
\mathrm{ms}^{-1}\end{array}$ & $\begin{array}{c}V_{W} \\
\mathrm{~ms}^{-1}\end{array}$ & $\begin{array}{c}c \\
\mathrm{~ms}^{-1}\end{array}$ & $\mathrm{k}$ & $\begin{array}{c}V_{\text {avg }}^{3} \\
\text { obs }\end{array}$ & $\begin{array}{c}\left(V_{\text {avg }}\right)^{3} \\
\text { obs }\end{array}$ & EPF & $\begin{array}{c}\text { P } \\
\mathrm{Wm}^{2}\end{array}$ \\
\hline Jan. & 3 & 3.02 & 3.42 & 2.11 & 25.16 & 21.41 & 1.17 & 18.41 \\
Feb. & 2.94 & 2.97 & 3.51 & 1.93 & 21.53 & 16.73 & 1.28 & 14.36 \\
Mar. & 3.14 & 3.16 & 3.67 & 2.42 & 27.64 & 23.86 & 1.15 & 17.21 \\
Apr. & 3.1 & 3.05 & 3.63 & 2.03 & 27.33 & 24.12 & 1.13 & 17.53 \\
May & 3.22 & 3.17 & 3.77 & 2.49 & 29.25 & 27.35 & 1.07 & 19.55 \\
Jun. & 3.53 & 3.49 & 3.95 & 2.64 & 40.31 & 38.27 & 1.05 & 25.74 \\
Jul. & 3.66 & 3.61 & 4.12 & 2.78 & 48.31 & 47.11 & 1.02 & 31.66 \\
Aug. & 3.48 & 3.37 & 3.81 & 2.43 & 39.86 & 37.16 & 1.07 & 26.86 \\
Sept. & 3.2 & 3.21 & 3.74 & 2.47 & 29.76 & 27.15 & 1.09 & 18.37 \\
Oct. & 2.72 & 2.74 & 3.44 & 1.88 & 18.63 & 16.14 & 1.15 & 14.22 \\
Nov. & 2.48 & 2.47 & 3.06 & 1.77 & 13.93 & 11.13 & 1.25 & 10.44 \\
Dec. & 2.75 & 2.79 & 3.31 & 1.91 & 18.54 & 16.03 & 1.15 & 13.92 \\
\hline
\end{tabular}

Table 2. Seasonal mean wind speed characteristic parameters for the period 2008-2018.

\begin{tabular}{ccccccccc}
\hline Season & $\begin{array}{c}V_{\text {obs }} \\
\mathrm{ms}^{-1}\end{array}$ & $\begin{array}{c}V_{W} \\
\mathrm{~ms}^{-1}\end{array}$ & $\begin{array}{c}c \\
\mathrm{~ms}^{-1}\end{array}$ & $\mathrm{k}$ & $\begin{array}{c}V_{\text {avg }}^{3} \\
\text { obs }\end{array}$ & $\begin{array}{c}\left(V_{\text {avg }}\right)^{3} \\
\text { obs }\end{array}$ & $\mathrm{EPF}$ & $\begin{array}{c}\mathrm{P} \\
\mathrm{Wm}^{2}\end{array}$ \\
\hline Spring & 3.15 & 3.18 & 3.44 & 2.06 & 27.76 & 25.17 & 1.1 & 18.87 \\
Summer & 3.55 & 3.61 & 3.71 & 2.11 & 41.83 & 39.24 & 1.06 & 27.63 \\
Autumn & 2.8 & 2.76 & 3.12 & 1.81 & 20.12 & 18.73 & 1.07 & 15.44 \\
Winter & 2.9 & 2.95 & 3.22 & 1.93 & 22.31 & 20.92 & 1.06 & 15.94 \\
\hline
\end{tabular}


Table 3. Annual mean wind speed characteristic parameters for the period 2008-2018.

\begin{tabular}{ccccccccc}
\hline Months & $\begin{array}{c}V_{\text {obs }} \\
\mathrm{ms}^{-1}\end{array}$ & $\begin{array}{c}V_{W} \\
\mathrm{~ms}^{-1}\end{array}$ & $\begin{array}{c}c \\
\mathrm{~ms}^{-1}\end{array}$ & $\mathrm{k}$ & $\begin{array}{c}V_{\text {avg }}^{3} \\
\mathrm{obs}\end{array}$ & $\begin{array}{c}\left.\mathrm{V}_{\text {avg }}\right)^{3} \\
\mathrm{obs}\end{array}$ & $\mathrm{EPF}$ & $\begin{array}{c}\mathrm{P} \\
\mathrm{Wm}^{2}\end{array}$ \\
\hline 2008 & 3.25 & 3.28 & 3.67 & 1.82 & 32.83 & 30.14 & 1.09 & 21.16 \\
2009 & 3.41 & 3.4 & 3.78 & 1.77 & 38.06 & 35.71 & 1.06 & 25.44 \\
2010 & 3.13 & 3.15 & 3.75 & 1.83 & 28.94 & 26.45 & 1.09 & 18.21 \\
2011 & 3.14 & 3.15 & 3.73 & 1.96 & 28.92 & 26.31 & 1.1 & 18.25 \\
2012 & 3.17 & 3.16 & 3.86 & 1.74 & 29.11 & 26.95 & 1.08 & 18.34 \\
2013 & 3.31 & 3.33 & 3.91 & 1.82 & 34.74 & 32.61 & 1.06 & 23.18 \\
2014 & 2.87 & 2.91 & 3.41 & 2.01 & 21.88 & 20.13 & 1.08 & 15.76 \\
2015 & 2.96 & 2.93 & 3.45 & 1.75 & 24.23 & 22.16 & 1.09 & 16.45 \\
2016 & 2.97 & 2.94 & 3.51 & 1.86 & 24.38 & 22.37 & 1.09 & 16.77 \\
2017 & 2.88 & 2.92 & 3.67 & 1.79 & 21.93 & 19.87 & 1.1 & 15.83 \\
2018 & 3.02 & 3.05 & 3.78 & 1.86 & 26.62 & 24.17 & 1.1 & 18.33 \\
\hline
\end{tabular}

the maximum $\mathrm{k}(2.11)$ in summer and minimum (1.81) in autumn. The values of the shape parameter for the whole dataset were found around 2, which represents that the wind speed was below moderate values at a $10 \mathrm{~m}$ height at the candidate site. The average scale parameter in $\mathrm{m} / \mathrm{s}$ was found to be 3.62 for the monthly mean wind speed, 3.37 for seasonal values and 3.68 for annual basis. The maximum scale parameter values were recorded in July $(4.12 \mathrm{~m} / \mathrm{s})$, in 2013 $(3.91 \mathrm{~m} / \mathrm{s})$ and during summer season $(3.71 \mathrm{~m} / \mathrm{s})$, while the minimum $\mathrm{c}$ values were found to be in November $(3.06 \mathrm{~m} / \mathrm{s})$, in $2015(3.45 \mathrm{~m} / \mathrm{s})$ and during autumn season $(3.12 \mathrm{~m} / \mathrm{s})$.

To sum up, the values of the shape and scale parameters present seasonal variation and increased at the beginning of the year until reach their maximum values in summer months and then decreased towards the autumn months. The EPF was calculated according to the relation above, it was found that EPF values greater than 1 which indicates that the mean power density for the month, season and year is greater than the mean power density at the monthly, seasonally and annual mean.

The observed $\left(\mathrm{v}_{\mathrm{obs}}\right)$ and estimated $\left(\mathrm{v}_{\mathrm{w}}\right)$ values of the mean wind speed values were compared and presented in Figures 6-8 as well as displayed in Tables 1-3. The Wiebull model underestimates the monthly wind speeds, the maximum observed/Weibull mean wind speed values in $\mathrm{m} / \mathrm{s}$ are 3.66/3.61 in July, while the minimum values are 2.48/2.47 in November. Seasonally, it was found that Weibull model overestimates the mean wind speeds with a maximum value of observed/Weibull wind speed $3.55 / 3.61 \mathrm{~m} / \mathrm{s}$ and was found to be in summer season. The underestimation of monthly values and overestimation of seasonal values are due to the tendency of Weibull distribution, however this distribution is underestimate lower and upper wind speed intervals, while overestimate intermediate wind speed intervals [35]. Annually, it was found that Weibull model 


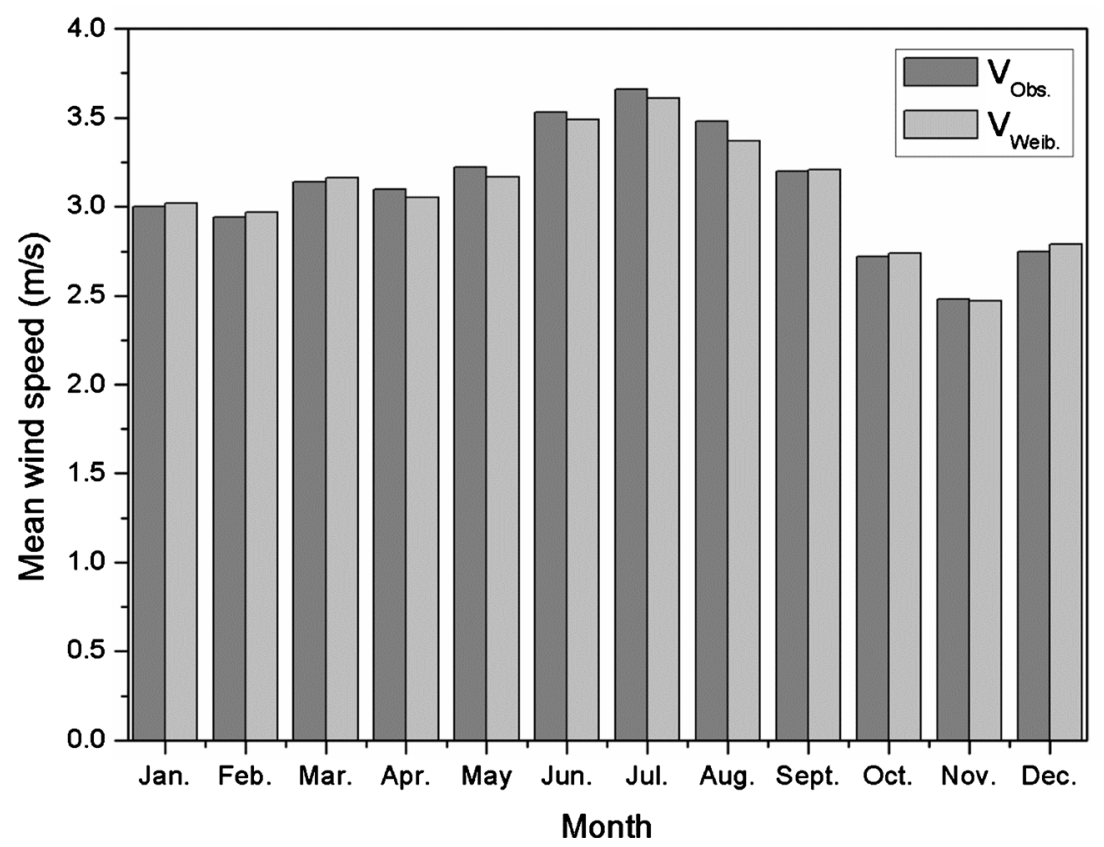

Figure 6. Observed and estimated monthly mean wind speed values for the period 2008-2018.

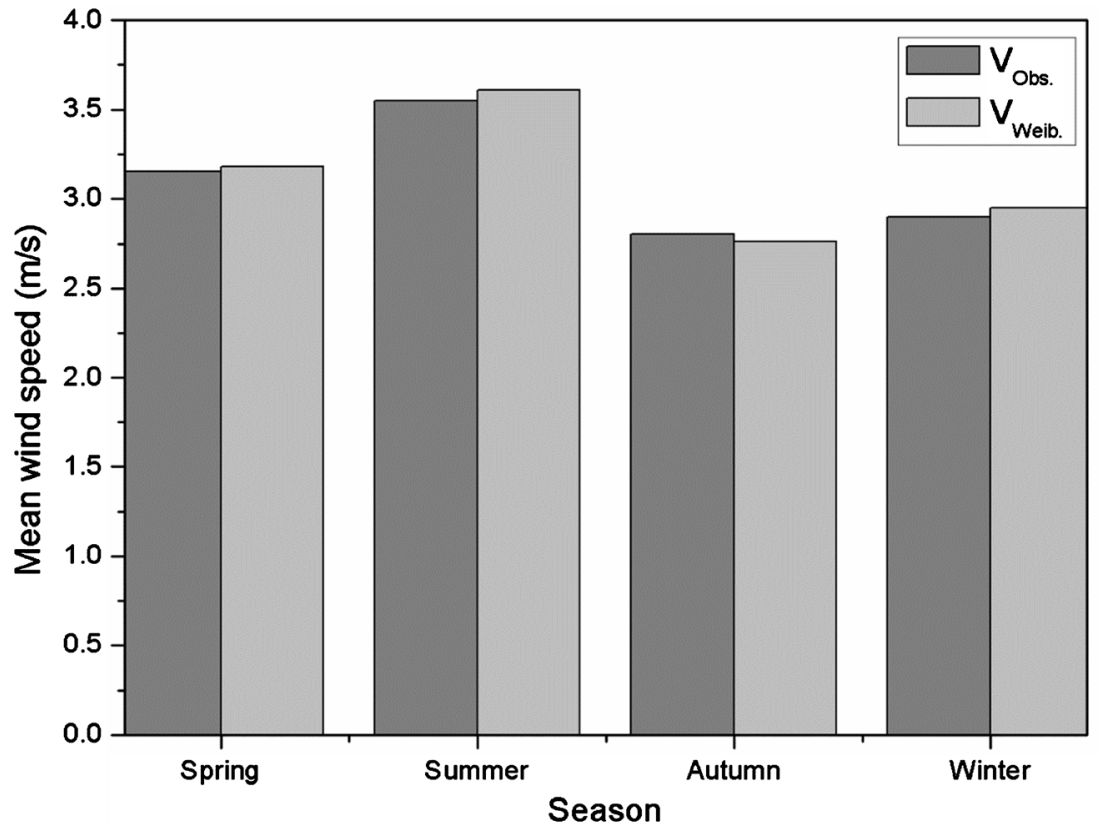

Figure 7. Observed and estimated seasonal mean wind speed values for the period 2008-2018.

overestimates the mean wind speeds in the all the years except 2012-2016 which showed an underestimation of the mean wind speeds. Maximum observed/Weibull mean wind speed $3.31 / 3.33 \mathrm{~m} / \mathrm{s}$ was found in 2013 , while the minimum values of observed/Weibull mean wind speed 2.87/2.93 m/s was found in 2014 .

Figure 9 \& Figure 10 represents the scatter plot and polynomial fit of the monthly and annually mean wind speed versus mean wind power. The coefficients 


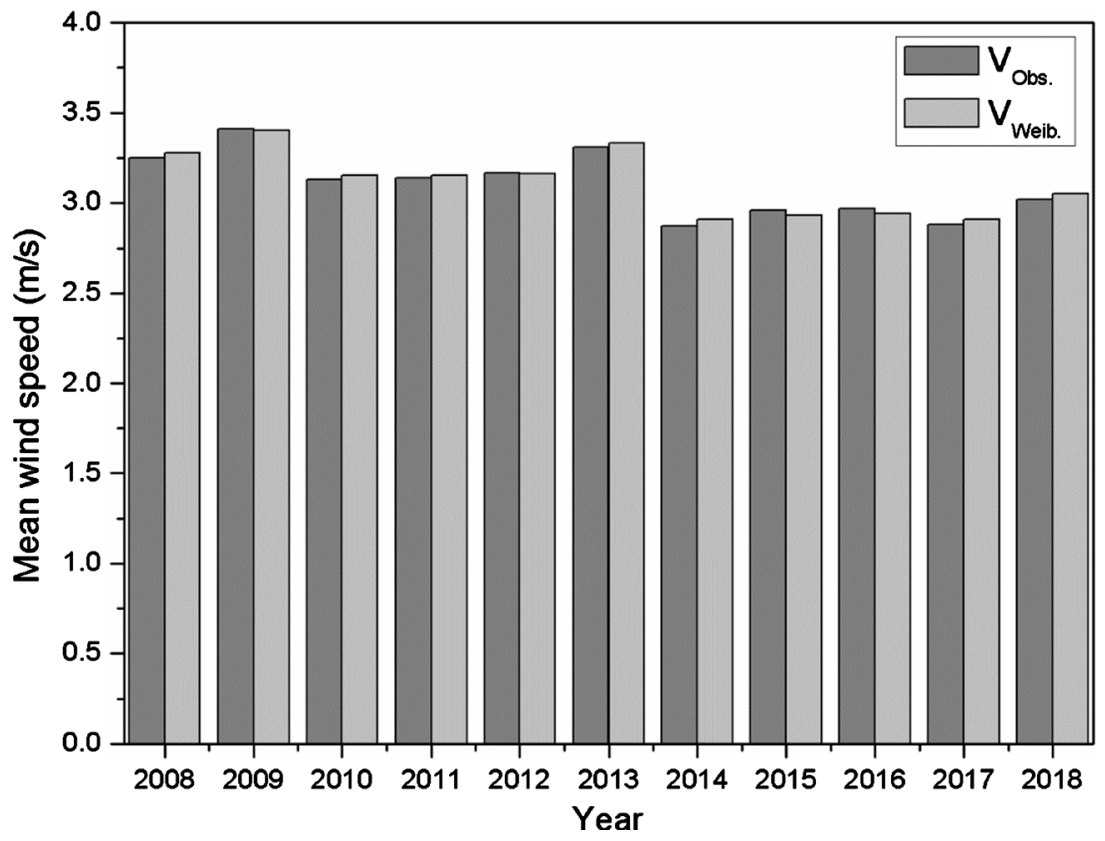

Figure 8. Observed and estimated annual mean wind speed values for the period 2008-2018.

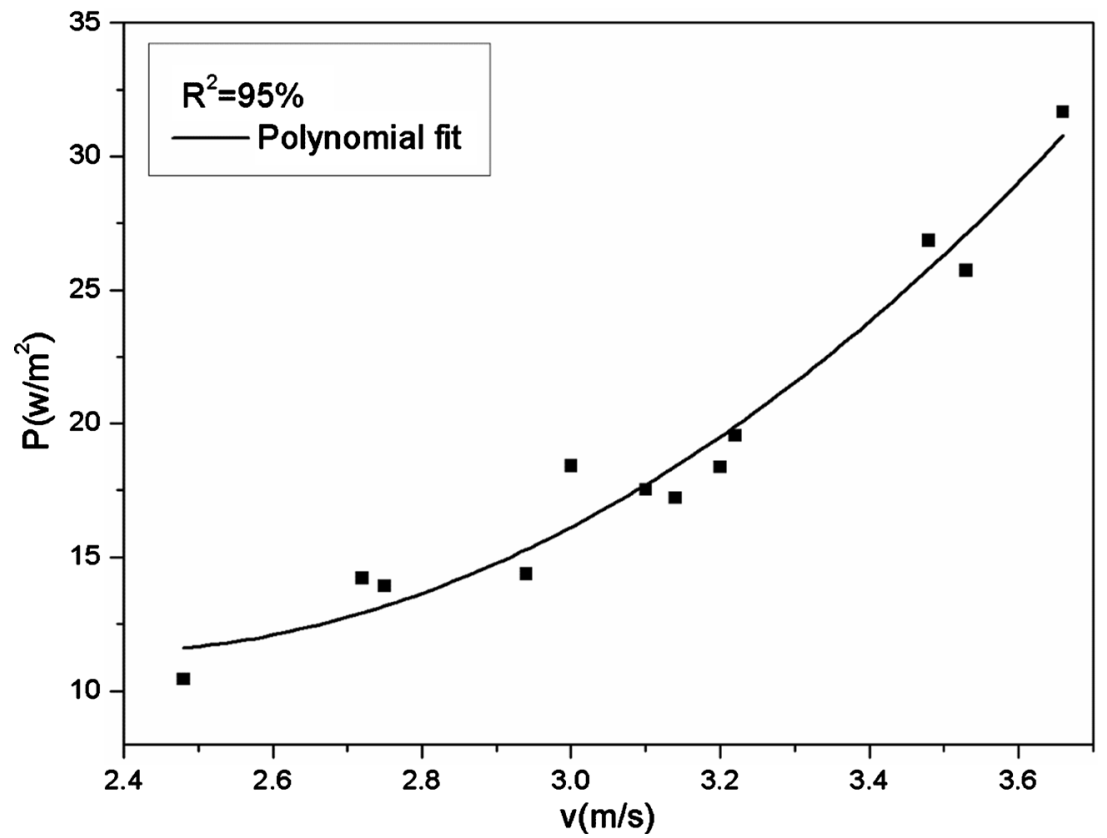

Figure 9. Scatter plot and polynomial fit of monthly mean speed versus monthly mean wind power for the period 2008 to 2018 .

of determination $\mathrm{R}^{2}$ were found to be $95 \%$ and $96 \%$ for the monthly and annually mean wind speed respectively. Table 4 presents the fitting parameters where $b_{1}$ is the coefficient of wind speed and $b_{2}$ is the standard error. The maximum monthly mean wind power was found in July $\left(31.66 \mathrm{w} / \mathrm{m}^{2}\right)$, while the minimum value was found in November $\left(10.44 \mathrm{w} / \mathrm{m}^{2}\right)$, however, July and November months represents respectively the maximum and minimum monthly mean 
Table 4. Polynomial fit parameters.

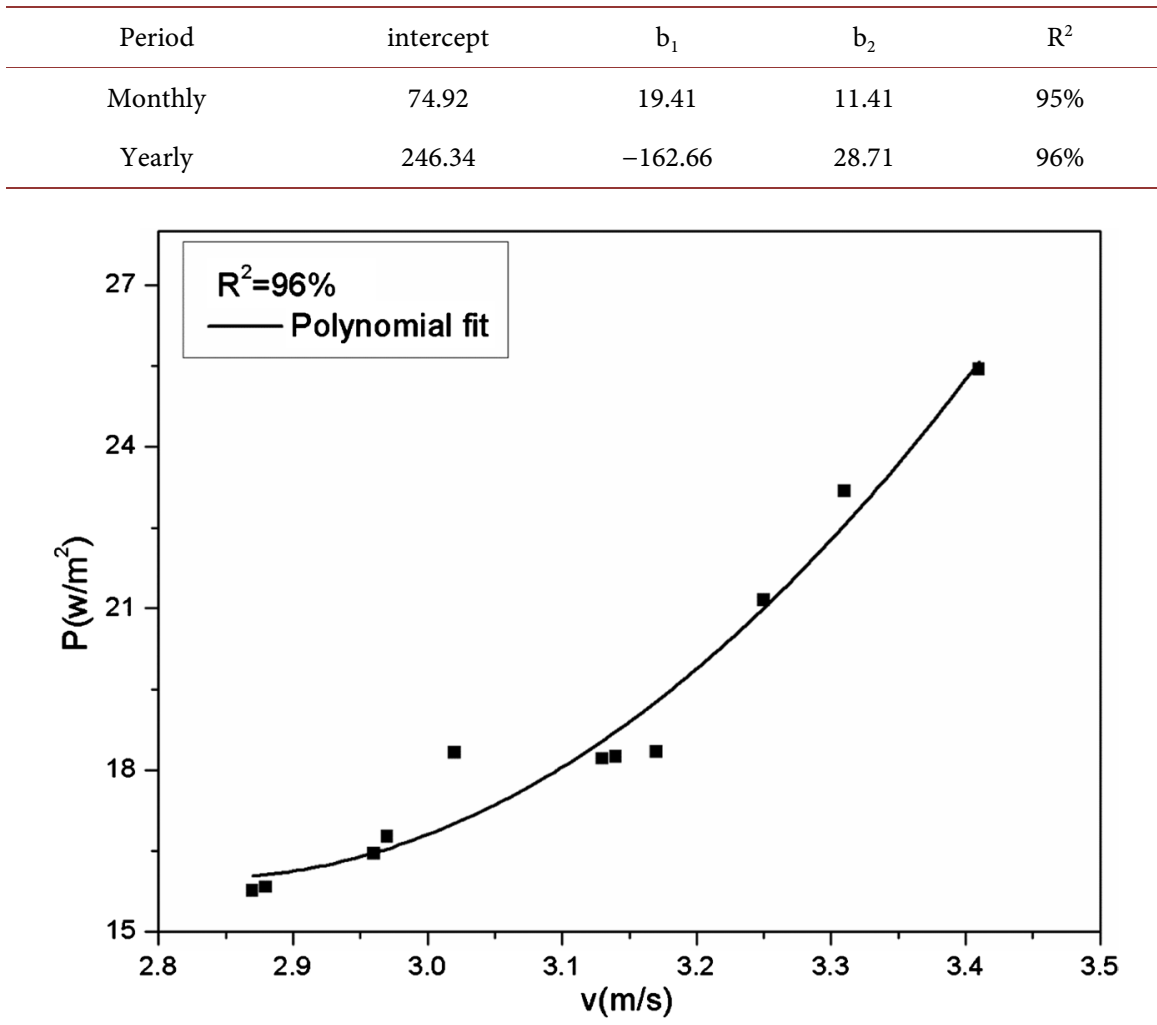

Figure 10. Scatter plot and polynomial fit of yearly mean speed versus yearly mean wind power for the period 2008 to 2018.

wind speed. The maximum/minimum annual mean power $23.18 / 15.76 \mathrm{w} / \mathrm{m}^{2}$ were found in 2013 and 2014 respectively. A seasonal variation of the monthly mean wind power (highest in summer months) was found which indicates that summer season has the maximum mean power with a value of $27.63 \mathrm{w} / \mathrm{m}^{2}$.

\section{Conclusion}

In this work, the study of wind speed variation at a site in eastern Jerusalem was conducted in order to have a clear understanding of the energy potential at the site and localized the necessary characteristics of wind parameters. The developed Weibull distribution model from the measured wind speeds was applied to estimate the wind power density. The study was conducted on monthly, seasonal and annual basis. The relation between mean wind power and mean wind speed was fitted by the second-order polynomial function. The highest average maximum values were found to be $5.7 \mathrm{~m} / \mathrm{s}$ in June 2008 , whereas the mean maximum values ranged from $5.4 \mathrm{~m} / \mathrm{s}$ in June to $3.8 \mathrm{~m} / \mathrm{s}$ in November. The mean minimum values ranged from $2 \mathrm{~m} / \mathrm{s}$ in July to $1.2 \mathrm{~m} / \mathrm{s}$ in November. In general, a seasonal variation of the wind speed values was found with higher values in summer months. The mean wind power was also calculated, the highest mean power value was found to be $31.66 \mathrm{w} / \mathrm{m}^{2}$ in July with a maximum value of 23.18 $\mathrm{w} / \mathrm{m}^{2}$ in 2013. This study benefits from the use of a large dataset and the draw- 
back of this dataset is that they are close to the surface, often located in areas not actually adapted to wind project development. The results can be applied to all studies using surface measurements and could be followed by more precise studies at precise locations at different altitudes above the ground. Further investigations can be done to study whether or not the wind distribution and Weibull parameters vary a lot with the altitude, also, the study of the ability of Weibull distribution and its estimation to cover wind speeds interval frequencies.

\section{Acknowledgements}

The data was provided by the Palestinian meteorological stations network office.

\section{Conflicts of Interest}

The authors declare no conflicts of interest regarding the publication of this paper.

\section{References}

[1] Juaidi, A.F., Montoya, G., Ibrik, I.H. and Manzano-Agugliaro, F. (2016) An Overview of Renewable Energy Potential in Palestine. Renewable Sustainable Energy Review, 65, 943-960. https://doi.org/10.1016/j.rser.2016.07.052

[2] Albisher, H. and Alsamamra, H. (2019) An Overview of Wind Energy Potentials in Palestine. Journal of Energy and Natural Resources, 8, 98-108.

https://doi.org/10.11648/j.jenr.20190803.11

[3] Kitaneh, R., Alsamamra, H. and Aljunaidi, A. (2012) Modeling of Wind Energy in Some Areas of Palestine. Energy Conversion and Management, 62, 64-69. https://doi.org/10.1016/j.enconman.2012.04.008

[4] Basel, E. and Yaseen, T.Q. (2007) Renewable Energy Applications in Palestine, An-Najah National University, Nablus.

[5] Palestinian Central Bureau of Statistics (2016) Mean Wind Speed in Palestine by Station.

[6] Badawi, S.A., Hasbullaha, N.F., Yusoff, S.H. and Hashim, A. (2019) Energy and Power Estimation for Three Different Locations in Palestine. Indonesian Journal Electrical Engineering and Computer Science, 14, 1049-1056.

https://doi.org/10.11591/ijeecs.v14.i3.pp1049-1056

[7] Fadare, D.A. (2008) A Statistical Analysis of Wind Energy Potential in Ibadan, Nigeria, Based on Weibull Distribution Function. The Pacific Journal of Science and Technology, 9, 115-126.

[8] Mayhoub, A.B. and Azzam, A. (1997) A Survey on the Assessment of Wind Energy Potential in Egypt. Renewable Energy, 11, 235-247. https://doi.org/10.1016/S0960-1481(96)00113-9

[9] Gul, M., Tai, N., Huang, W., Nadeem, M. and Yu, M. (2019) Assessment of Wind Power Potential and Economic Analysis at Hyderabad in Pakistan: Powering to Local Communities Using Wind Power. Sustainability, 11, 1391. https://doi.org/10.3390/su11051391

[10] Luna, R.E. and Chuch, H.W. (1974) Estimation of Long-Term Concentration Using a Universal Wind Speed Distribution. Journal of Applied Meteorology, 13, 910-916. https://doi.org/10.1175/1520-0450(1974)013<0910:EOLTCU >2.0.CO;2 
[11] Zhou, J., Erdem, E., Li, G. and Shi, J. (2010) Comprehensive Evaluation of Wind Speed Distribution Models: A Case Study for North Dakota. Energy Conversion and Management, 51, 1449-1458.https://doi.org/10.1016/j.enconman.2010.01.020

[12] Justus, C.G. and Amir, M. (1976) Height Variation of Wind Speed and Wind Distribution Statistics. Geophysical Research Letters, 3, 261-264.

https://doi.org/10.1029/GL003i005p00261

[13] John, F.W. and Nicholas, J. (1997) Wind Energy Technology. Wiley, New York.

[14] Zhou, W., Yang, H.X. and Fang, Z.H. (2006) Wind Power Potential and Characteristic Analysis of the Pearl River Delta Region, China. Renewable Energy, 31, 739-753. https://doi.org/10.1016/j.renene.2005.05.006

[15] Elamouri, M. and Amar, F.B. (2008) Wind Energy Potential in Tunisia. Renewable Energy, 33, 758-768. https://doi.org/10.1016/j.renene.2007.04.005

[16] Kombe, E. and Muguthu, J. (2019) Wind Energy Potential Assessment of Great Cumbrae Island Using Weibull Distribution Function. Journal of Energy Research Reviews, 2, 1-8. https://doi.org/10.9734/jenrr/2019/v2i229734

[17] Van der Auwera, L., de Meyer, F., and Malet, L.M. (1980) The Use of the Weibull Three-Parameter Model for Estimating Mean Wind Power Densities. Journal of Applied Meteorology, 19, 819-825. https://doi.org/10.1175/1520-0450(1980)019<0819:TUOTWT>2.0.CO;2

[18] Rehman, S., Halawani, T.O. and Husain, T. (1994) Weibull Parameters for Wind Speed Distribution in Saudi Arabia. Solar Energy, 53, 473-479.

https://doi.org/10.1016/0038-092X(94)90126-M

[19] Celik, A. (2003) Weibull Representative Compressed Wind Speed Data for Energy and Performance Calculations of Wind Energy Systems. Energy Conversion and Management, 44, 3057-3072.https://doi.org/10.1016/S0196-8904(03)00075-X

[20] Rehman, S. and Al-Abbadi, N.M. (2008) Wind Shear Coefficient, Turbulence Intensity and Wind Power Potential Assessment for Dhulom, Saudi Arabia. Renewable Energy, 33, 2653-2660. https://doi.org/10.1016/j.renene.2008.02.012

[21] Bassyouni, M., Gutub, S.A. and Javaid, U. (2015) Assessment and Analysis of Wind Power Resource Using Weibull Parameters. Energy Explore Exploitation, 33, 105-122. https://doi.org/10.1260/0144-5987.33.1.105

[22] Mohammadi, K., Alavi, O. and Mostafaeipour, A. (2016) Assessing Different Parameters Estimation Methods of Weibull Distribution to Compute Wind Power Density. Energy Conversion and Management, 108, 322-335. https://doi.org/10.1016/j.enconman.2015.11.015

[23] Nassar, F.Y. and Alsadi, Y.S. (2019) Assessment of solar Energy Potential in Gaza Strip-Palestine. Sustainable Energy Technologies and Assessments, 31, 318-328. https://doi.org/10.1016/j.seta.2018.12.010

[24] Shabbaneh, R. and Hasan, A. (1997) Wind Energy Potential in Palestine. Renewable Energy, 11, 479-483.https://doi.org/10.1016/S0960-1481(96)00111-5

[25] Ismail, M.S., Moghavvemi, M. and Mahlia, T.M.I. (2013) Energy Trends in Palestinian Territories of West Bank and Gaza Strip: Possibilities for Reducing the Reliance on External Energy Sources. Renewable and Sustainable Energy Reviews, 28, 117-129. https://doi.org/10.1016/j.rser.2013.07.047

[26] Burton, T., Sharpe, D., Jenkins, N. and Bossanyi, E. (2001) Wind Energy-Handbook. Wiley and Sons Ltd., New York.

[27] Manwell, J.F., McGowan, J.G. and Rogers, A.L. (2010) Wind Energy Explained: Theory, Design and Application. John Wiley \& Sons Ltd., Chichester. 
https://doi.org/10.1002/9781119994367

[28] Albani, A. and Ibrahim, M.Z. (2017) Wind Energy Potential and Power Law Indexes Assessment for Selected Near-Coastal Sites in Malaysia. Energies, 10, 307-320. https://doi.org/10.3390/en10030307

[29] Usta, I, Arik, I. and Yenilmez, I. (2018) A new Estimation Approach Based on Moments for Estimating Weibull Parameters in Wind Power Applications. Energy Conversion and Management, 164, 570-578. https://doi.org/10.1016/j.enconman.2018.03.033

[30] Persaud, S., Flynn, D. and Fox, B. (1999) Potential for Wind Generation on the Guyana Coastlands. Renewable Energy, 18, 175-189. https://doi.org/10.1016/S0960-1481(98)00793-9

[31] Ulgen, K. and Hepbasli, A. (2002) Determination of Weibull Parameters for Wind Energy Analysis of Izmir, Turky. International Journal of Energy Research, 26, 495-506. https://doi.org/10.1002/er.798

[32] Khahro, S.F., Tabbassum, K., Soomro, A.M., Dong, L. and Liao, X. (2014) Evaluation of Wind Power Production Prospective and Weibull Parameter Estimation Methods for Babaurband, Sindh Pakistan. Energy Conversion and Management, 78, 956-967. https://doi.org/10.1016/j.enconman.2013.06.062

[33] Singh, K., Bule, L. and Khan, M. (2019) Wind Energy Resource Assessment for Vanuatu with Accurate Estimation of Weibull Parameters. Energy Explore Exploitation, 37, 1804-1832. https://doi.org/10.1177/0144598719866897

[34] Katinas, V., Marciukaitis, M. and Gecevicius, G. (2017) Statistical Analysis of Wind Characteristics Based on Weibull Methods for Estimation of Power Generation in Lithuania. Renewable Energy, 113, 190-201. https://doi.org/10.1016/j.renene.2017.05.071

[35] Elena, G., Fidel, G., Pedro, J, Navarro, J. and Montavez, J. (2008) The Influence of the Weibull Assumption in Monthly Wind Energy Estimation. Wind Energy, 11, 483-502. https://doi.org/10.1002/we.270 